\title{
Oculopalpebral Dimensions of Adult Nigerians: Report from the Enugu Normative Ocular Anthropometry Study
}

\author{
Boniface I. Eze Judith N. Uche Jude O. Shiweobi Chibuike N. Mba \\ Department of Ophthalmology, University of Nigeria Teaching Hospital (UNTH), Ituku-Ozalla, Enugu, Nigeria
}

\section{Key Words}

Oculopalpebral • Anthropometric dimensions • Adults •

Nigeria

\begin{abstract}
Objective: To determine the normal oculopalpebral anthropometric measurements of a Nigerian adult population. Subjects and Methods: A population-based prospective observational random survey was conducted in Enugu, SouthEastern Nigeria between January and April 2010. The participants were healthy adults comprising 248 males and 252 females aged 18-76 years. One thousand eyes were examined. Demographic data, and bilateral direct manual millimetre measurements of the horizontal palpebral fissure (HPF), vertical palpebral fissure (VPF), upper lid crease (ULC), brow height $(\mathrm{BH})$, and margin reflex distance (MRD) were obtained from all participants. Data were categorised by demographic variables and analysed to yield frequencies, percentages and proportions. Between-gender comparisons, using the independent $t$ test, were considered significant at $p<$ 0.05. Results: The mean age of the participants was $36.5 \pm$ 14.6 years. There was no significant difference between the genders in mean age (men: $37.3 \pm 15.7$ vs. women: $35.8 \pm$ $13.3, p=0.2302)$. The mean values of the parameters were
\end{abstract}

(male, female) HPF: $32.8 \pm 2.0$ vs. $32.6 \pm 3.0$; VPF: $10.6 \pm 1.2$ vs. $10.6 \pm 1.2 ;$ ULC: $8.2 \pm 2.5$ vs. $7.9 \pm 2.2 ; \mathrm{BH}: 13.1 \pm 2.4$ vs. $13.6 \pm 2.7$; and MRD: $4.1 \pm 0.5$ vs. $4.2 \pm 0.8$. Significant between-gender difference was observed only in $\mathrm{BH}$ measurements ( $p=0.029)$ and variable trends with age. Conclusion: Oculopalpebral measurements of normal adult Nigerians in Enugu showed variations by age and gender. This may have implications for clinical evaluation and surgical management of oculopalpebral disorders in adult South-Eastern Nigerians. Future longitudinal studies are needed.

Copyright $\odot 2012$ S. Karger AG, Basel

\section{Introduction}

Normal periocular anthropometric measurements are fundamental topographic anatomical parameters utilised in clinical ophthalmology $[1,2]$, optometry [1] and the ophthalmic industry $[1,3]$. Further, normal anthropometric studies generate reference data for studies in craniofacial dysmorphology $[1,4]$ and comparative physical anthropology $[1,5]$. Specifically, normative data on the oculopalpebral anthropometric parameters are indispensable in the accurate clinical interpretation of palpebral disease and serve as reference points during cosmetic and recon-

\section{KARGER}

Fax +4161306 1234

E-Mail karger@karger.ch

www.karger.com
(C) 2012 S. Karger AG, Basel

$1011-7571 / 13 / 0221-0075 \$ 38.00 / 0$

Accessible online at:

www.karger.com/mpp
Dr. B.I. Eze

Department of Ophthalmology, University of Nigeria Teaching Hospital (UNTH) PMB 01139, Ituku-Ozalla

Enugu, Enugu State (Nigeria)

Tel. +234 803316 5767, E-Mail xy3165767@yahoo.com 
structive surgical interventions in the eyelids. Like other periocular measurements, the normal values of palbebral dimensions are age-, gender-, and race/ethnicity-dependent [5-8]. Therefore, there is a need for clinicians to factor in these demographic variables while arriving at anatomic endpoints during medical and or surgical interventions aimed at reversing pathological derangements of these parameters. Although various methods of periocular anthropometric measurement - manual anthropometry using millimetre rule or callipers, two-dimensional photography and three-dimensional photogrammetry exist, none is superior to the other in terms of measurement accuracy and repeatability [9-11]. Thus, the preference for a particular measurement technique is dictated by availability of requisite human and material resources, and cost. There are many published reports on periocular anthropometric surveys dominated by reports from outside Africa $[1,2,4,6]$. The lack of large-scale populationbased anthropometric reference data on indigenous black Africans [12] has necessitated the reliance on data from other continents, in arriving at crucial clinical decisions on treatment endpoints. Therefore, the investigators conducted a population-based survey of healthy adult SouthEastern Nigerians.

\section{Subjects and Methods}

The study was a population-based prospective observational random survey conducted in Enugu State, South-Eastern Nigeria, between January and April 2010. One thousand eyes of 500 randomly selected healthy Ibo and non-Ibo adults aged 18-76 years were examined.

Enugu town is the administrative capital of Enugu state, one of the five constituent states of the south-east geopolitical zone of Nigeria. Of Nigeria's six geopolitical zones, the south-east zone is populated predominantly by ethnic Ibos. Geographically, the south-east geopolitical zone is located in the tropical rain forest climatic belt with two seasons in the year - the rainy and dry seasons. The zone's inhabitants are predominantly civil servants, traders, farmers, and artisans. Being cosmopolitan, the population of Enugu town is drawn largely from her component rural areas, other states in the zone, and beyond; consequently, the town's indigenes account for a small proportion of the population.

Prior to commencement of the study, ethical clearance, consistent with the 1964 Helsinki Declaration was obtained from the Ethics Committee (Institution Review Board) of the University of Nigeria Teaching Hospital, Enugu.

Exclusion criteria were adults who had congenital and/or acquired ocular or periocular craniofacial or systemic conditions likely to affect the values of any of the anthropometric parameters of interest, and potential participants who had mixed parentage. Specifically, subjects with history of ocular/periocular surgery or trauma and those who had eyelid positional abnormality, orbitoocular or eyelid tumour, phthisis bulbi, and those who had ciliary or superciliary madarosis were excluded. Also were excluded subjects who had systemic conditions such as thyroid-related orbitopathy, diabetes mellitus, myasthenia gravis and those on ocular or systemic medications that can affect the measured parameters.

Participants' demographic data (sex and age) were recorded. Bilateral direct manual millimetre measurements of their horizontal palpebral fissure (HPF), vertical palpebral fissure (VPF), upper eyelid crease (ULC), brow height (BH) and margin reflex distance (MRD) were made. The measurement procedure was according to the technique described by Oztürk et al. [1].

\section{Operational Definitions}

HPF: distance between the medial and lateral canthus; VPF: distance between the upper and lower lid margins measured at the pupillary midline; ULC: distance between the upper eyelid lashline and the ULC in downgaze; $\mathrm{BH}$ : distance from the upper eyelid lashline to the inferior border of the eyebrow at its highest point; MRD: distance between the upper eyelid margin and the corneal light reflex at the centre of the pupil.

\section{Measurement Technique}

Measurements were obtained by the four investigators (B.I.E., J.N.U., C.N.M. and J.O.S.) after satisfactory practice of the procedures and attainment of excellent interobserver agreement in measurement values. All measurements were taken with a transparent plastic millimetre rule (China Arts Hangzhou Import and Export Inc., Hangzhou, China). The measurements were obtained with the subject and the observer comfortably seated in a well-illuminated room, and their eyes at the same horizontal level. Except for ULC which was measured in downgaze position, all other measurements were taken with the subjects' eyes in the primary position of gaze. For measurement of MRD, the observer illuminated the pupil with a bright pen torch (Keeler Instruments, Windsor, United Kingdom) held in one hand while measurement was taken with the other hand. Each measurement was taken 3 times in each eye and averaged; the mean of the three measurements was entered for analysis. For all the parameters, because the measured values did not differ between the two eyes, the data on both eyes $(n=1,000)$ were entered for analysis. Data were collated statistically, categorised by demographic variables, and analysed using the Statistical Package for Social Sciences (SPSS) software, version 18. Data were subjected to descriptive and analytical statistical analysis to yield frequencies, percentages, proportions, and means. Statistical tests for significant differences were performed using the independent $t$ test. In all, a $p<0.05$ was considered statistically significant.

\section{Results}

The mean age of the participants was $36.5 \pm 14.6$ years. Although the males (age range: $18-76$ years, mean age: $37.3 \pm 15.7)$ had a wider age range compared with the females (18-74 years, mean age: $35.8 \pm 13.3)$, there was no significant statistical difference in mean age $(\mathrm{p}=$ 0.2302). The demographic characteristics of the study participants are shown in table 1. 
Table 1. Demographic characteristics of the 500 study subjects

\begin{tabular}{llll}
\hline \multirow{2}{*}{ Age } & \multicolumn{2}{c}{ Sex } & $\mathrm{n}(\%)$ \\
\cline { 2 - 3 } & male & female & \\
\hline $18-20$ years & 50 & 53 & $103(20.6 \%)$ \\
$21-40$ years & 62 & 65 & $127(25.4 \%)$ \\
$41-60$ years & 72 & 68 & $140(28.0 \%)$ \\
$61-80$ years & 64 & 66 & $130(26.0 \%)$ \\
\hline Total & $248(49.6 \%)$ & $252(50.4 \%)$ & $500(100.0 \%)$ \\
\hline
\end{tabular}

Table 2. Mean \pm standard deviation values of the measured parameters by sex

\begin{tabular}{lrrlll}
\hline Parameter & \multicolumn{2}{l}{ Sex } & t value & $\mathrm{p}$ \\
\cline { 2 - 3 } & \multicolumn{1}{l}{ male } & \multicolumn{1}{l}{ female } & & \\
\hline HPF & $32.8 \pm 2.0$ & $32.6 \pm 3.0$ & & 0.88 & 0.382 \\
VPF & $10.6 \pm 1.2$ & $10.6 \pm 1.2$ & & no difference \\
ULC & $8.2 \pm 2.5$ & $7.9 \pm 2.2$ & & 1.43 & 0.155 \\
BH & $13.1 \pm 2.4$ & $13.6 \pm 2.7$ & & 2.19 & 0.029 \\
MRD & $4.1 \pm 0.5$ & $4.2 \pm 0.8$ & & 1.67 & 0.095 \\
\hline
\end{tabular}

Table 3. Mean \pm standard deviation of the measured parameters by age and sex

\begin{tabular}{|c|c|c|c|c|c|c|c|c|}
\hline & male & female & male & female & male & female & male & female \\
\hline VPF & $10.9 \pm 0.8$ & $10.6 \pm 0.9$ & $10.6 \pm 1.0$ & $10.7 \pm 1.1$ & $10.7 \pm 1.5$ & $10.5 \pm 1.5$ & $10.3 \pm 1.4$ & $10.1 \pm 1.4$ \\
\hline ULC & $8.5 \pm 2.0$ & $7.9 \pm 2.0$ & $8.1 \pm 1.8$ & $8.2 \pm 2.2$ & $7.7 \pm 2.4$ & $7.5 \pm 2.3$ & $8.4 \pm 4.1$ & $7.5 \pm 1.8$ \\
\hline $\mathrm{BH}$ & $12.8 \pm 1.8$ & $13.7 \pm 2.0$ & $13.1 \pm 2.2$ & $13.7 \pm 2.8$ & $12.8 \pm 2.2$ & $13.4 \pm 2.6$ & $13.2 \pm 3.2$ & $13.5 \pm 3.6$ \\
\hline
\end{tabular}

Across all ages, the mean values of the VPF measurements were the same for both sexes; however, the mean values of HPF, although higher in males, did not differ significantly from that of females $(32.8 \pm 2.0$ vs. $32.6 \pm$ $3.0, \mathrm{t}=0.88, \mathrm{p}=0.382$ ) (table 2 ). Although the mean value of ULC was higher in males there was no significant between-gender difference in the mean measurements of ULC $(t=1.43, p=0.155)$. The mean values of $\mathrm{BH}$ measurements were significantly higher in females $(t=2.19$, $\mathrm{p}=0.029$ ) (table 2). The overall mean measurement of MRD was higher in females $(4.2 \pm 0.8)$ compared with males $(4.1 \pm 0.5)$. The observed difference, however, did not reach the level of statistical significance $(t=1.67, \mathrm{p}=$ 0.095). In males and females, the values of HPF differed by age, being lowest in the 18 - to 20 -year age group, increasing to a plateau which spanned through 21- to 40and 41 - to 60 -year age groups, and dropping off again in the 61- to 80-year age group (table 3). In females, the HPF value was highest in the 41 - to 60 -year age group and lowest in the 61- to 80-year group.

In both sexes, the mean value of the ULC was lowest in the 41- to 60-year age group; however, the values peaked in the 18 - to 20 -year age group in males and in the 21 - to 40 -year group for females. The mean values of $\mathrm{BH}$ measurements for each age group were higher in females than males. Intra-sex examination of the temporal trend of this parameter showed that males had a peak value in their 7th-8th decades of life and lowest in the 18- to 20 and 41 - to 60 -year age groups. In females, the value was highest in the 41- to 60-year-old, and lowest in the 18- to 20 - and 21- to 40 -year age groups (table 3 ). The peak value of this parameter was recorded in the 21- to 40-year age group for males, and in the 21- to 40- and 41- to 60 year age groups for females; in both sexes, the lowest mean value (males: $3.8 \pm 0.6$, females: $3.7 \pm 0.5$ ) was observed in the 61- to 80 -year age group.

\section{Discussion}

The 18- to 76-year age range of the survey participants was similar to that reported by Takahagi et al. [5] in Brazil, but differed from the reports in Turkey [1, 13-15], the Netherlands [6], Zaire [12] and Malaysia [16], Spain [17], Korea [18], United States of America [19] and China [20]. However, the participants' gender distribution was similar to that of other reports $[1,5,6,12,14]$. While previous surveys $[1,6,12,13,15,19]$ included paediatric partici- 
pants, the present study like that of Takahagi et al. [5] was on adults only. Although the participants in the Chinese [20] and Turkish [14] studies were adults only, these surveys were specific for young adults aged $18-25$ years. The age differences in these studies could have implications for interpretation, utility and between-survey comparisons of results, which suggests the need to restrict future surveys to specific age groups.

Overall, there was no significant gender-determined difference in the mean values of HPF and VPF; however, the age trend, in both males and females, of the two parameters showed higher values in the 21- to 40 - and 41- to 60 -year age groups compared with the 18- to 20 - and 61to 80 -year groups. The absence of gender differences in the means of HPF and VPF is consistent with the findings by Oztürk et al. [1] but differed from the higher male values, of both parameters, reported by Van den Bosch et al. [6], Koz et al. [21], and other reports in Turkey [14] and Singapore [16]. The mean values of HPF and VPF in the present study were higher than the values obtained from the studies of Arabs [1], Orientals from Japan and Brazil [5], African-Americans [2] and Caucasian [2, 6] populations. The observed discrepancies probably reflect ethnic differences between the study populations, variable ages of study participants or both. While the low mean values observed in the 18- to 20-year-olds could be attributed to possible selection bias arising from the comparatively smaller number of participants in this age group and narrow bin width, the trend in other age groups is consistent with other reports $[1,6,22]$ and reflects normal age-related changes in periocular anatomy. The present data provide guidance for clinical end point decisions on palpebral fissure dimensions of adults in Enugu, Nigeria. Although discretely higher in men than women, the mean ULC measurement did not differ significantly by gender. In both sexes, the mean ULC measurement demonstrated modest variability across all the age groups. While the ULC values in the present report are comparable with those reported by Kristina et al. [2] on African-Americans, they are higher than the values obtained from similar studies on Turkish [1], Japanese [5], and Brazilian [5] subjects and lower than the measurements obtained in American Caucasians [2]. Furthermore, the present data partially agrees with a Turkish [15] report, which, although it did not find any significant age-determined variation in ULC values, had higher ULC in females. The observed variability of ULC measurements between surveys on different ethnic groups and the similarity of the measured ULC values with those of black African Americans probably further underscore the dominant role of racial background in the determination of periocular anatomical parameters. These findings have significant clinical import for clinicians attending adults from the study area. Overall, the mean BH measurement was significantly higher in females than males. Also, the means of the discrete measurements of this parameter were higher in females across all age groups. This confirmed the results of Kristina et al. [2] and Van den Bosch et al. [6], and partially agrees with the findings of Oztürk et al. [1], who had higher mean $\mathrm{BH}$ values for males in the 12to 20- and 41- to 60-year age groups. Whereas the wider bin width of the under- 20 age group in the series of Oztürk et al. [1] might partly explain the discrepancies, ethnically determined differences in the pace and pattern of age-related changes in periocular topographic anatomy probably explain the discordant observations in the 41- to 60 -year age group. As pointed out by Van den Bosch et al. [6], cosmetic brow alopecia and epilation of eye lashes, a common practice in females, could influence brow measurements. Fortunately, such cases were excluded in the present study. Therefore, the present study provides gender-specific anthropometric data in adults of Enugu, Nigeria, utilisable during aesthetic or reconstructive brow repositioning procedures. The average MRD measurement, which, overall did not differ significantly by gender, tended to drop off from the age of 60 years in both males and females. The observed age-related downward shift in MRD, which is attributable to laxity/stretching of medial and lateral canthal tendons associated with aging [6], is consistent with the reports in the Netherlands [5] and Brazil [6]. The MRD values observed in the present study tended to be higher, across all age groups, than the values obtained on Orientals and Brazilian of Japanese descent [5]. Again, differences in ethnic and environmental factors likely explain the discrepancy. The result seems to suggest that age, not gender, is the paramount demographic factor in the clinical assessment and determination of surgical treatment goals of vertical upper lid malpositions in adults in Enugu, Nigeria. The present study did not observe any interocular asymmetry across all the oculopalpebral anthropometric parameters investigated. While this sharply contrasts the findings in Korean [18], American [19], and Zairian [12] populations, the majority of previous similar surveys [1-11,13-17,21,22] did not report on the symmetry of their findings, thus precluding further between-survey comparisons. Given this scenario of limited availability of specific comparative data, the present findings suggest that ethnic and environmental influences probably account for this observation. This highlights the need for future periocular anthropometric 
studies to capture and report data on the interocular symmetry of the anthropometric parameter/s investigated. Additionally, these studies should consider angle measurement techniques, especially for those parameters that did not differ by gender, for interocular comparisons.

The limitations of this study include its cross-sectional design, which precluded the determination of longitudinal trend in individual study participants. This would have been more informative than comparing different participants in different age groups. Additionally, between-survey differences in measurement techniques probably call to question the validity of comparing the present results with those obtained elsewhere using nonmanual measurement techniques.

\section{Conclusions}

This study showed that age, and to a limited extent gender, were important demographic determinants of the normative oculopalpebral anthropometric dimensions of adults in South-Eastern Nigeria. The findings may have implications for provision of periocular clinical and surgical care for the study population. Future longitudinal studies of similar nature are warranted.

\section{References}

-1 Oztürk F, Yavas G, Inam UU: Normal periocular anthropometric measurements in the Turkish population. Ophthalmic Epidemiol 2006;13:145-149.

-2 Kristina M, Preeya K, Woodward JA, Stinnet SS, Murchison AP: Eyebrow and eyelid dimensions: anthropometric analysis of African Americans and Caucasians. Plast Reconstr Surg 2009; 124:615-623.

>3 Tang CY, Tang N, Stewart MC: Facial measurements for frame. Optom Vis Sci 1998;75: 288-292.

4 Gupta VP, Sodhi PK, Pandey RM: Normal values for inner intercanthal, interpupillary, and outer intercanthal distances in the Indian population. Int J Clin Pract 2003;57: 25-29.

5 Takahagi RU, Schellini SA, Padovani CR, Ideta Shinji, Katori N, Nakamura Y: Oriental oculopalpebral dimensions: quantitative comparison between orientals from Japan and Brazil. Clin Ophthalmol 2008;2:563567.

6 Van den Bosch WA, Leenders I, Mulder P Topographic anatomy of the eyelids, and the effects of sex and age. Br J Ophthalmol 1999; 83:347-352.

7 Evereklioglu C, Doganay S, Er H, Tercan M, Balat A, Cumurcu T: Craniofacial anthropometry in Turkish population. Cleft Palate Craniofac J 2002;39:208-218.
$>8$ Barreto RL, Mathog RH: Orbital measurements in black and white populations. Laryngoscope 1999;109:1051-1054.

9 Ghouddosi H, Elder R, Haeers P, Wertheim D, Greenhill D: Comparison of three methods of facial measurements. Int J Oral Maxillofac Surg 2007;36:250-258.

10 Ozsoy U, Demirel BM, Yildirim FB, Tosun $\mathrm{O}$, Sarikcioglu L: Method selection in craniofacial measurements: advantages and disadvantages of 3D digitisation method. J Craniomaxillofac Surg 2009;37:285-290.

11 Nunes TP, Oliveria TF, Matayoshi S: A comparative study of the manual and digital measurements of the palbebral fissure (in Portuguese). Arq Bras Oftalmol 2005;68: 785-287.

12 Kaimbo Wa Kaimbo D: Palbebral measurements in healthy subjects in Zaire (in French). J Fr Ophtalmol 1995;18:286-291.

13 Everekliogu C, Doganay S, Er H, Gunduz A, Tercan M, Balat A, Cumurcu T: Craniofacial anthropometry in a Turkish population. Cleft Palate Craniofac J 2002;39:208-218.

14 Bozkir MG, Karakas P, Oguz O: Measurements of soft tissue orbits in Turkish adults. Surg Radiol Anat 2003;25:54-57.

15 Erbagci I, Erbagci H, Kizilkan N, Gumusburun E, Bekir N: The effect of age and gender on the anatomic structure of Caucasian healthy eyelids. Saudi Med J 2005;26:15351538 .
16 Ngeow WC, Aljunid ST: Craniofacial anthropometric norms of Malays. Singapore Med J 2009;50:525-528.

17 Siqueira M, Joaquim A, Schellini SA, Padovani CR, Cruz AA: Eyelid alterations after the age of 50 years (in Portuguese). Arq Bras Oftalmol 2005;68:285-290.

18 Song WC, Kim SJ, Kim SH, Hu KS, Kim HJ, Koh KS: Asymmetry of the palpebral fissure and upper eyelid crease in Koreans. J Plast Reconstr Aesthet Surg 2007;60:251-255.

19 Lam BL, Lam S, Walls RC: Prevalence of palpebral fissure asymmetry in white persons. Am J Ophthalmol 1995;120:518-522.

20 Wu XS, Jian XC, He ZJ, Gao X, Zhong X: Investigation of anthropometric measurements of anatomic structures of orbital soft tissue in 102 young Han Chinese adults. Ophthal Plast Reconstr Surg 2010;26:339343 .

21 Koz GO, Can I, Kural G: Turk toolumunda goz kapagi yapisinin anatomic ve fonksiyonei duzeyde arastinlmasi. MN Oftalmol 2002;1:77-81.

22 Hill JC: An analysis of the senile changes in the palpebral fissure. Can J Ophthalmol 1975;10:32-35. 